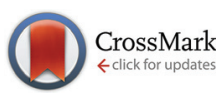

Cite this: Analyst, 2015, 140, 1832

Received 8th January 2015, Accepted 2nd February 2015

DOI: 10.1039/c5an00039d

www.rsc.org/analyst

\section{"One-drop-of-blood" electroanalysis of lead levels in blood using a foam-like mesoporous polymer of melamine-formaldehyde and disposable screen-printed electrodes $\uparrow$}

\author{
Yanfang Zhao, ${ }^{a, b}$ Lubin Xu, ${ }^{\text {a,b }}$ Shuying Li, ${ }^{a}$ Qi Chen, ${ }^{a}$ Daoshan Yang, ${ }^{a}$ Lingxin Chen ${ }^{c}$ \\ and Hua Wang*a
}

A foam-like mesoporous polymer of melamine-formaldehyde (mPMF) was synthesized and further deposited on disposable screen-printed electrodes (SPEs) for the electroanalysis of $\mathrm{Pb}^{2+}$ ions in blood. Investigations indicate that the prepared MPMF is ultrastable in water, showing a mesoporous structure and an amine-rich composition, as characterized by electronic microscopy images and IR spectra. Importantly, it possesses a highly-selective chelating ability and a powerful absorbent capacity for $\mathrm{Pb}^{2+}$ ions. By way of solid-state $\mathrm{PbCl}_{2}$ voltammetry, the mPMF-modified sensor could allow for the detection of $\mathrm{Pb}^{2+}$ ions in one drop of blood with a high detection selectivity, sensitivity (down to about $0.10 \mu \mathrm{g} \mathrm{L}^{-1} \mathrm{~Pb}^{2+}$ ions) and reproducibility. Such a simple "one-drop-of-blood" electroanalysis method equipped with disposable SPEs and a portable electrochemical transducer can be tailored for the field-deployable or on-site monitoring of blood $\mathrm{Pb}^{2+}$ levels in the clinical laboratory.

Lead $(\mathrm{Pb})$ is a toxic heavy metal commonly found in the natural environment and in some consumer products. ${ }^{1}$ The exposure of the human body to lead usually occu4s through ingestion, inhalation or dermal contact, and thus almost everyone has some measurable level of lead in their blood. ${ }^{2}$ When lead enters a human's bloodstream it may elevate their blood lead level, which can result in lead poisoning and certain serious diseases. For example, children are prone to the health effects of lead, causing potentially permanent learning and behavioral disorders. ${ }^{3}$ As of 2012, the Centers for Disease Control and Prevention (US) has set the standard levels of lead poison-

\footnotetext{
${ }^{a}$ School of Chemistry and Chemical Engineering, Qufu Normal University, Qufu City 273165, China. E-mail: huawangqfnu@126.com; Fax: +86 537 4456306; Tel: +865374456306

${ }^{b}$ College of Chemistry and Pharmaceutical Science, Qingdao Agricultural University, Qingdao 266109, China

${ }^{c}$ Key Laboratory of Coastal Environmental Processes and Ecological Remediation, Yantai Institute of Coastal Zone Research, Chinese Academy of Sciences,

Yantai 264003, China

$\dagger$ Electronic supplementary information (ESI) available. See DOI: 10.1039/ c5an00039d
}

ing and elevated blood lead for adults and children to be about $100.0 \mu \mathrm{g} \mathrm{L}^{-1}$ and $50.0 \mu \mathrm{g} \mathrm{L}^{-1}$, respectively. ${ }^{4}$ Methods to evaluate blood lead levels and thus ensure timely treatment so as to avoid lead poisoning are of great importance. To date, many detection methods have been applied for detecting blood lead ions, and most are based on atomic absorption spectroscopy (AAS) ${ }^{5}$ and inductively coupled plasma mass spectrometry. ${ }^{6-8}$ However, these sensitive methods generally require expensive instruments, professional skill and complicated sample pretreatment, which may be limiting for the insite evaluation or monitoring of lead poisoning. Therefore, developing a simple, fast, sensitive, selective and field-deployable detection method for probing blood lead levels has become an interesting and attractive target to pursue.

Electrochemical detection technologies, which are of low cost and which possess high sensitivities, easy operation and portable devices for on-site applications, have been widely applied for the detection of $\mathrm{Pb}^{2+}$ ions. ${ }^{9,10}$ For example, anodic stripping voltammetry in combination with mercury drop electrodes or mercury film electrodes was established for the sensitive detection of $\mathrm{Pb}^{2+} \cdot{ }^{11-14}$ However, the toxicity of mercury might cause it to be undesirable for wide sensing applications. Additionally, most solid electrodes reported so far encounter some drawbacks, such as a troublesome modification procedure, risk of cross-contamination, electrode poisoning and cost ineffectiveness. Alternatively, screen-printed electrodes (SPEs) have been increasingly employed in electrochemical analysis strategies due to their outstanding advantages over conventional solid-state electrodes, such as being cost effective, disposable, easy to carry and simple to modify, and thanks to their potential for mass production. ${ }^{15-18}$ Particularly, the miniaturized size of SPEs can allow for on-site tests using volume-saving samples such as one drop of blood. Moreover, a variety of functional species, such as bismuth, ${ }^{19,20}$ gold, ${ }^{21,22}$ antimony, ${ }^{23}$ diazonium salts, ${ }^{24,25}$ graphene ${ }^{26}$ and multiwalled carbon nanotubes, ${ }^{27}$ etc. , have been employed to modify SPEs, with the aim to facilitate the sensitive detection of $\mathrm{Pb}^{2+}$ ions in different matrices. However, these surface modification 
methods can suffer from limited stabilities and detection performances in addition to complicated preparation routes and/ or expensive reagents.

In recent decades, porous organic polymers have rapidly emerged for their use in diverse applications, such as catalysis, adsorption, separation, sensors and biotechnology. ${ }^{28}$ As an important example, a mesoporous polymer of melamine-formaldehyde (mPMF), which is generally prepared via a polycondensation reaction using melamine and formaldehyde, can possess many interesting physicochemical properties, such as a high aqueous stability, large surface area, efficient catalysis and fast absorption kinetics. ${ }^{29-32}$ In particular, mPMF has been recognized to present a considerably high absorption capacity for $\mathrm{Pb}^{2+}$ ions. ${ }^{32}$ To the best of our knowledge, however, the outstanding absorption ability of mPMF has not yet been applied to the detection of $\mathrm{Pb}^{2+}$ ions. In the present work, mPMF was successfully synthesized and further deposited on disposable SPEs for the direct probing of lead levels in one drop of blood with high sensitivity and selectivity by electrochemical square-wave voltammetry (SWV) of solid-state $\mathrm{PbCl}_{2}$.

The morphological structure of MPMF was first examined by transmission electron microscopy (TEM) imaging, showing foam-like mesoporous characteristics for the mPMF scaffolds (Fig. 1A). Meanwhile, scanning electron microscopy (SEM) images disclose that MPMF deposited on SPEs affords a mesoporous matrix and a rough surface (Fig. 1B), leading to a large surface area and potentially high absorption of the target $\mathrm{Pb}^{2+}$ ions. Furthermore, the chemical composition of mPMF was examined by FT-IR spectroscopy (Fig. S1 $\dagger$ ). The IR bands at $1570 \mathrm{~cm}^{-1}$ and $800 \mathrm{~cm}^{-1}$ can be attributed to a $\mathrm{C}=\mathrm{N}$ stretching vibration and a triazine ring, respectively, and the bands at $3467 \mathrm{~cm}^{-1}$ and $3419 \mathrm{~cm}^{-1}$ can be attributed to the -NH antisymmetric stretching vibration. Accordingly, triazine rings and aminal $\left(-\mathrm{NH}-\mathrm{CH}_{2}-\mathrm{NH}-\right)$ functional groups are thought to exist throughout the MPMF matrix, serving as strong chelating ligands for the capture of $\mathrm{Pb}^{2+}$ ions. ${ }^{32}$ Therefore, mPMF, with its mesoporous structure, large surface area and high aminechelating capacity, could be applied as an ideal absorbent for its deposition on electrodes for the sensing of $\mathrm{Pb}^{2+}$ ions.

The electroanalytical performances of the mPMF-modified SPEs were investigated for the sensing of $\mathrm{Pb}^{2+}$ ions and compared with those of chitosan-modified electrodes (Fig. 2), chitosan being a common absorbent with amine groups used
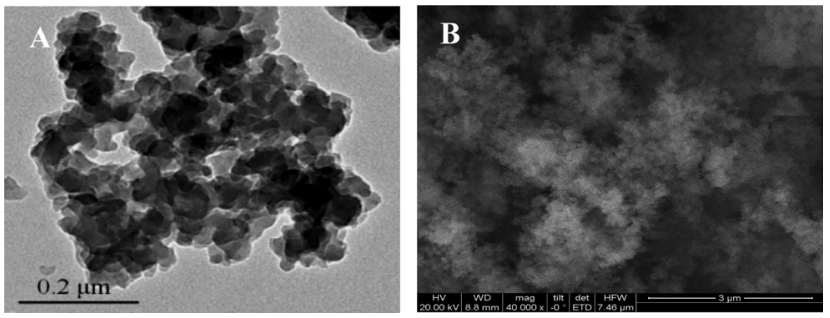

Fig. 1 (A) TEM image and (B) SEM image of mPMF prepared in suspension or deposited on a SPE, respectively.
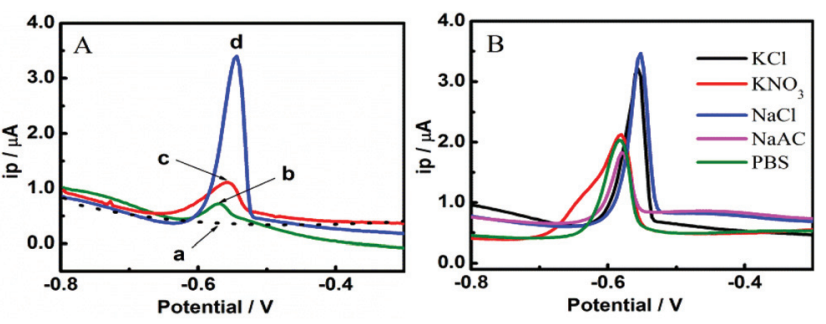

Fig. 2 (A) SWV responses to $\mathrm{Pb}^{2+}$ ions $\left(20 \mu \mathrm{g} \mathrm{L}^{-1}\right)$ in $0.10 \mathrm{M} \mathrm{NaCl}(\mathrm{pH}$ 6.0) for (b) bare SPEs, (c) chitosan-modified SPEs and (d) mPMFmodified SPEs, with (a) as the control (no $\mathrm{Pb}^{2+}$ ions); (B) SWV responses to $\mathrm{Pb}^{2+}$ ions $\left(20 \mu \mathrm{g} \mathrm{L}^{-1}\right)$ for the mPMF-modified SPEs in different supporting electrolytes $(0.10 \mathrm{M})$.

for adsorbing certain metal ions including $\mathrm{Pb}^{2+} \cdot{ }^{33,34}$ As shown in Fig. 2A, the mPMF-modified SPE could exhibit a much larger SWV response to $\mathrm{Pb}^{2+}$ ions (curve d) than the chitosanmodified one (curve $\mathbf{c}$ ) or the bare one (curve b). In addition, the control test indicates that the mPMF-modified SPE showed no response in the absence of $\mathrm{Pb}^{2+}$ ions (curve a). These data confirm that mesoporous mPMF with $\mathrm{Pb}^{2+}$-chelating amine groups could afford a highly selective and large $\mathrm{Pb}^{2+}$-absorption capacity so as to endow the MPMF-modified SPEs with a greatly enhanced electrochemical response to $\mathrm{Pb}^{2+}$ ions. Moreover, it was experimentally found that the supporting electrolytes could also play a vital role in the electrochemical analysis of $\mathrm{Pb}^{2+}$ ions. Fig. $2 \mathrm{~B}$ shows a comparison of the $\mathrm{SWV}$ responses of the mPMF-modified SPEs in several supporting electrolytes, including phosphate buffer saline (PBS), $\mathrm{KCl}, \mathrm{NaCl}, \mathrm{NaAc}$ and $\mathrm{KNO}_{3}$. It is clear that larger stripping currents and sharper peak definitions were obtained for the $\mathrm{Pb}^{2+}$ responses when using the chloride-containing electrolytes, i.e., sodium chloride and potassium chloride. The enhanced electrochemical signal output may presumably result from the formation of slightly soluble $\mathrm{PbCl}_{2}$, which might conduct more sensitive solid-state stripping voltammetry, as reported previously for AgCl. ${ }^{35-37}$ Also, the peak currents were found to depend on the $\mathrm{NaCl}$ concentration (data not shown), showing the highest peak current for $0.10 \mathrm{M} \mathrm{NaCl}$. It is of note that this tested electrolyte media is consistent with physiological saline $(0.9 \%$ or about $0.10 \mathrm{M} \mathrm{NaCl}$ ). Therefore, the mPMF-modified SPEs can be tailored for the direct detection of $\mathrm{Pb}^{2+}$ ions in blood samples.

Moreover, the voltammetric conditions of the MPMF-modified SPEs were studied with respect to detecting $\mathrm{Pb}^{2+}$ ions (Fig. 3). As can be seen in Fig. $3 \mathrm{~A}$, the $\mathrm{Pb}^{2+}$ stripping signals increased with increasing mPMF concentration up to $2.0 \mathrm{mg}$ $\mathrm{mL}^{-1}$, after which they decreased slightly, presumably due to an increase in electron-transport resistance. Furthermore, the effect of $\mathrm{pH}$ on the SWV response was explored, with the biggest response obtained at $\mathrm{pH} 6.0$ (Fig. 3B). This could be explained by the fact that the amine groups of MPMF might be protonated at lower $\mathrm{pH}$ values, thereby increasing the electrostatic repulsion of $\mathrm{Pb}^{2+}$ ions approaching the mPMF-modified SPEs. A decrease in the stability of the MPMF absorbent might also occur at lower $\mathrm{pH}$ values. In contrast, too high a $\mathrm{pH}$ value 

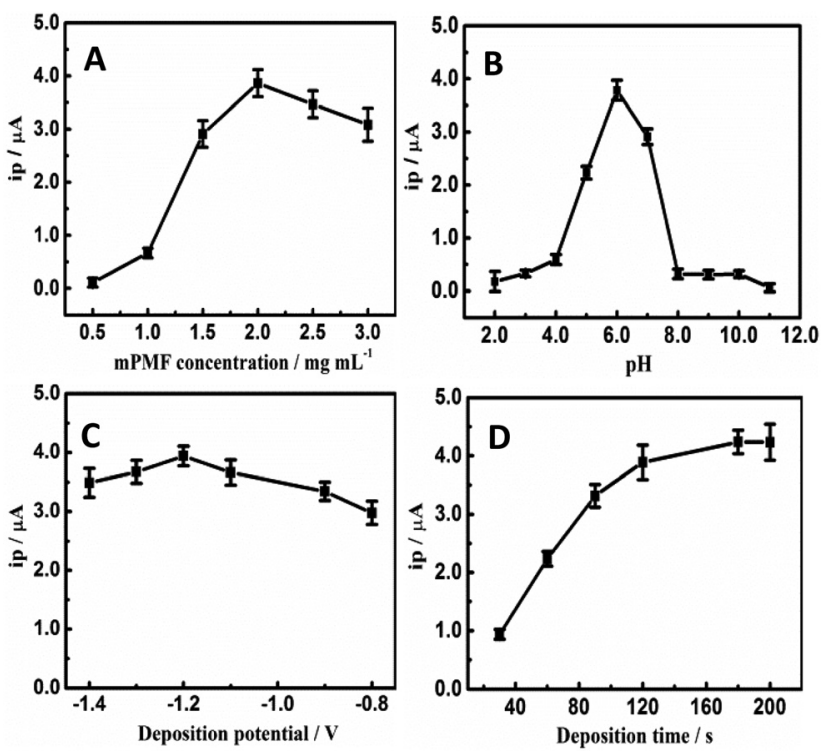

Fig. 3 The electrochemical SWV responses of the mPMF-modified SPEs to $\mathrm{Pb}^{2+}$ ions $\left(30 \mu \mathrm{g} \mathrm{L}^{-1}\right)$ depending on (A) concentration of $\mathrm{mPMF}$, (B) $\mathrm{pH}$ value, (C) deposition potential and (D) deposition time.

might cause the $\mathrm{Pb}^{2+}$ ions to hydrolyze and precipitate. In addition, the SWV responses to $\mathrm{Pb}^{2+}$ ions were found to be dependent on the electrochemical deposition potentials (Fig. 3C) and deposition time (Fig. 3D). By compromising, an optimal deposition potential of $-1.2 \mathrm{~V}$ and a time of $120 \mathrm{~s}$ were selected for the electrochemical $\mathrm{Pb}^{2+}$ sensing.

The electroanalysis of $\mathrm{Pb}^{2+}$ ions was carried out under the optimized conditions, showing a linear detection range of $1.0-100 \mu \mathrm{g} \mathrm{L}^{-1}$ (Fig. 4A). Herein, a linear equation of $I=0.1376 C+0.2904(R=0.9979)$ was obtained and the limit of detection (LOD) was estimated to be about $0.10 \mu \mathrm{g} \mathrm{L}^{-1}$, which is lower than those for most SPEs modified with other sensing materials (Table S2 $\dagger$ ). Subsequently, the mPMFmodified SPEs were applied for the detection of blood $\mathrm{Pb}^{2+}$ ions using one drop of blood for each measurement, each with different $\mathrm{Pb}^{2+}$ concentrations (Fig. 4B). Accordingly, the amount of $\mathrm{Pb}^{2+}$ ions in blood could be quantified in the linear range of $1.0-50 \mu \mathrm{g} \mathrm{\textrm {L } ^ { - 1 }}$.
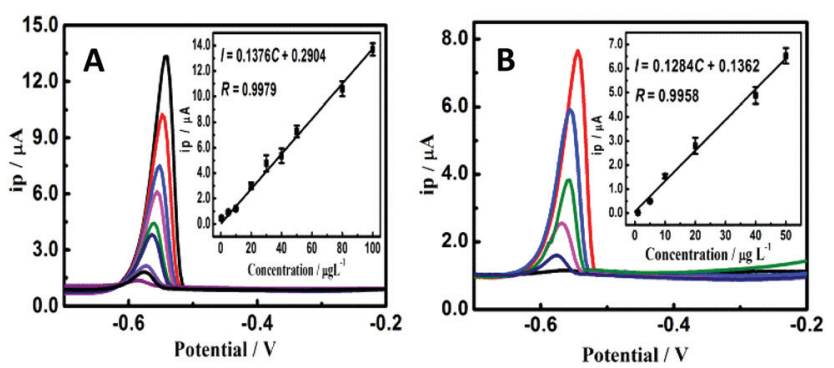

Fig. $4 \mathrm{SWV}$ responses of the mPMF-modified SPEs to $\mathrm{Pb}^{2+}$ ions with different concentrations in (A) $0.10 \mathrm{M} \mathrm{NaCl}(\mathrm{pH} \mathrm{6.0)}$ and (B) spiked blood, with the corresponding calibration plots (insets).
Furthermore, the feasible applicability of the proposed mPMF sensor for the practical detection of $\mathrm{Pb}^{2+}$ ions in blood samples was assessed using recovery tests, and compared with the AAS technology (Table S1 $\dagger$ ). Results indicate that the developed eletroanalysis method could be comparable to the classic method for the detection of $\mathrm{Pb}^{2+}$ ions in blood.

In addition, the interference of other ions which possibly co-exist in blood samples was evaluated (Fig. 5A). It was noted that the addition of 1000-fold excess concentrations of $\mathrm{K}^{+}$, $\mathrm{Mg}^{2+}, \mathrm{Ca}^{2+}, \mathrm{Fe}^{2+}, \mathrm{Fe}^{3+}, \mathrm{NO}_{3}{ }^{-}, \mathrm{SO}_{4}{ }^{2-}$ or $\mathrm{PO}_{4}{ }^{3-}$ ions caused no significant interference to the $\mathrm{Pb}^{2+}$ response. Also, 100-fold excess concentrations of $\mathrm{Cu}^{2+}$ and $\mathrm{Hg}^{2+}$ ions could induce deviations of within $\pm 10 \%$ only in the electrochemical $\mathrm{Pb}^{2+}$ response. In addition, the selective detection of $\mathrm{Pb}^{2+}$ ions could be achieved in the presence of at least a 20 -fold excess concentration of $\mathrm{Cd}^{2+}$ ions, showing a stripping peak well separated from that for $\mathrm{Pb}^{2+}$ ions. Such a high $\mathrm{Pb}^{2+}$ detection selectivity could be attributed to the specific and powerful absorption capacity of amine-functionalised mPMF for $\mathrm{Pb}^{2+}$ ions, where the nitrogen atoms of the mPMF unit can bind with $\mathrm{Pb}^{2+}$ ions in a $1: 4$ complexation mode, ${ }^{32}$ as schematically illustrated in Fig. 5B.

The reproducibility of the mPMF-modified SPEs for the detection of $\mathrm{Pb}^{2+}$ ions was investigated by monitoring the anodic peak responses to $\mathrm{Pb}^{2+}$ ions using six independent SPEs which were prepared from different batches (Fig. S2A $\dagger$ ). The relative standard deviation was found to be about $4.58 \%$ for six repetitions. The storage stability of the mPMF-modified

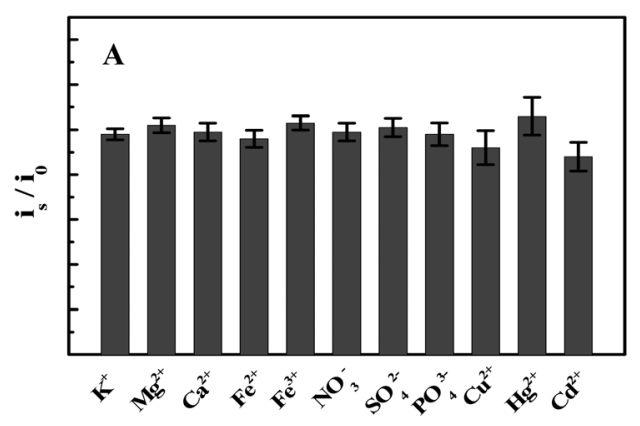

B<smiles></smiles>

Fig. 5 (A) The SWV responses of the mPMF-modified SPEs to $\mathrm{Pb}^{2+}$ ions $\left(40 \mu \mathrm{g} \mathrm{L}^{-1}\right)$ as current ratios $\left(I_{s} / I_{0}\right)$ in the presence of 1000 -fold excess concentrations of $\mathrm{K}^{+}, \mathrm{Mg}^{2+}, \mathrm{Ca}^{2+}, \mathrm{Fe}^{2+}, \mathrm{Fe}^{3+}, \mathrm{NO}_{3}{ }^{-}, \mathrm{SO}_{4}{ }^{2-}$ and $\mathrm{PO}_{4}{ }^{3-}$ ions, 100 -fold excess concentrations of $\mathrm{Cu}^{2+}$ and $\mathrm{Hg}^{2+}$ ions, and a 20fold excess concentration of $\mathrm{Cd}^{2+}$ ions, where $I_{\mathrm{s}}$ and $I_{0}$ refer to the SWV currents of $\mathrm{Pb}^{2+}$ ions in the presence and absence of interfering metal ions, respectively; (B) schematic of the possible interactions between $\mathrm{Pb}^{2+}$ ions and the mPMF deposited on the SPEs. 
SPEs was examined over different time intervals by comparing the responses to $40 \mu \mathrm{g} \mathrm{\textrm {L } ^ { - 1 }}$ of $\mathrm{Pb}^{2+}$ ions during 30 days (Fig. S2B $\dagger$ ). No observable change was witnessed over the testing period, revealing a satisfactory stability for the detection of $\mathrm{Pb}^{2+}$ ions due to the excellent aqueous stability of mPMF. In addition, the detection performances of the mPMFmodified SPEs were systematically compared with those of SPEs modified with other sensing materials (Table S2 $\dagger$ ). The results indicate that the developed mPMF sensor could present some advantages over most other detection methods for the sensing of $\mathrm{Pb}^{2+}$ ions.

In summary, mPMF was successfully synthesized with a foam-like mesoporous structure, high surface area, large amine density and aqueous ultra-stability. The mPMF-modified SPEs developed presented some outstanding advantages over the traditional detection technologies for the probing of $\mathrm{Pb}^{2+}$ ions in blood. Firstly, the highly selective chelating ability (1:4 complexation mode) and large absorption capacity of the mPMF for $\mathrm{Pb}^{2+}$ ions could endow the MPMF SPEs with the practical electroanalysis of blood $\mathrm{Pb}^{2+}$ ions with a high detection selectivity and sensitivity. Secondly, the aqueous ultrastability and fast absorption kinetics of mPMF bestowed the resulting sensor with rapid responses and a considerably high reproducibility and stability for $\mathrm{Pb}^{2+}$ detection. Thirdly, the ultra-sensitive signal output of solid-state $\mathrm{PbCl}_{2}$ voltammetry allowed for greatly enhanced $\mathrm{Pb}^{2+}$ electroanalysis performances as compared with the classic methods such as AAS technology. Forthly, the use of cheap and disposable SPEs as size-miniaturized sensing platforms allowed for $\mathrm{Pb}^{2+}$ analysis with significantly volume-saving samples, such as one drop of blood, which in combination with portable electrochemical transducers should allow for on-site testing. Therefore, the developed "one-drop-of-blood" electroanalysis candidate is promising for the extensive applications of real-time tests of blood lead levels in clinical diagnostics.

\section{Acknowledgements}

This work is supported by the National Natural Science Foundation of China (no. 21375075, 21302109 and 21302110), the Taishan Scholar Foundation of Shandong Province, Domestic Visiting Scholar Foundation for Young Backbone Teachers of Department of Education, Shandong Province, and Qingdao Agricultural University High-Level Personnel Funds (630736), Qingdao, P. R. China.

\section{Notes and references}

1 H. Pattee and D. J. Pain, Handb. Ecotoxicol., 2003, 2, 373398.

2 M. Markowitz, Pediatr. Rev., 2000, 21, 327-335.

3 D. Bellinger, A. Leviton, E. Allred and M. Rabinowitz, Environ. Res., 1994, 66, 12-30.

4 M. S. Burns and S. L. Gerstenberger, Am. J. Public Health, 2014, 104, e27-e33.
5 F. Shah, T. G. Kazi, H. I. Afridi, N. Naeemullah, M. B. Arain and J. A. Baig, J. Hazard. Mater., 2011, 192, 1132-1139.

6 J. A. Nunes, B. L. Batista, J. L. Rodrigues, N. M. Caldas, J. A. Neto and F. Barbosa Jr., J. Toxicol. Environ. Health, Part A, 2010, 73, 878-887.

7 R. Gajek, F. Barley and J. She, Anal. Methods, 2013, 5, 21932202.

8 S. D'Ilio, C. Majorani, F. Petrucci, N. Violante and O. Senofonte, Anal. Methods, 2010, 2, 2049-2054.

9 F. Arduini, J. Q. Calvo, G. Palleschi, D. Moscone and A. Amine, TrAC, Trends Anal. Chem., 2010, 29, 1295-1304.

10 G. Aragay and A. Merkoçi, Electrochim. Acta, 2012, 84, 49-61.

11 L. C. Martiniano, V. R. Abrantes, S. Y. Neto, E. P. Marques, T. C. Fonseca, L. L. Paim, A. G. Souza, N. R. Stradiotto, R. Q. Aucélio and G. H. Cavalcante, Fuel, 2013, 103, 11641167.

12 M. Ghoneim, A. Hassanein, E. Hammam and A. Beltagi, Fresenius. J. Anal. Chem., 2000, 367, 378-383.

13 J. A. Rodrigues, C. M. Rodrigues, P. J. Almeida, I. M. Valente, L. M. Gonçalves, R. G. Compton and A. A. Barros, Anal. Chim. Acta., 2011, 701, 152-156.

14 C. L. da Silva and J. C. Masini, Fresenius. J. Anal. Chem., 2000, 367, 284-290.

15 K. C. Honeychurch and J. P. Hart, TrAC, Trends. Anal. Chem., 2003, 22, 456-469.

16 O. D. Renedo, M. Alonso-Lomillo and M. Martinez, Talanta, 2007, 73, 202-219.

17 M. Li, Y. T. Li, D. W. Li and Y. T. Long, Anal. Chim. Acta., 2012, 734, 31-44.

18 X. Niu, M. Lan, H. Zhao, C. Chen, Y. Li and X. Zhu, Anal. Lett., 2013, 46, 2479-2502.

19 C. Chen, X. Niu, Y. Chai, H. Zhao and M. Lan, Sens. Actuators, B, 2013, 178, 339-342.

20 N. Serrano, A. Alberich, J. M. Díaz-Cruz, C. Ariño and M. Esteban, TrAC, Trends. Anal. Chem., 2013, 46, 15-29.

21 S. Laschi, I. Palchetti and M. Mascini, Sens. Actuators, B, 2006, 114, 460-465.

22 G. Martínez-Paredes, M. B. González-García and A. CostaGarcía, Electrochim. Acta, 2009, 54, 4801-4808.

23 M. Maczuga, A. Economou, A. Bobrowski and M. I. Prodromidis, Electrochim. Acta, 2013, 114, 758-765.

24 S. Bouden, A. Chaussé, S. Dorbes, O. El Tall, N. Bellakhal, M. Dachraoui and C. Vautrin-Ul, Talanta, 2013, 106, 414-421.

25 S. Bouden, N. Bellakhal, A. Chaussé and C. Vautrin-Ul, Electrochem. Commun., 2014, 41, 68-71.

26 H. Chao, L. Fu, Y. Li, X. Li, H. Du and J. Ye, Electroanalysis, 2013, 25, 2238-2243.

27 U. Injang, P. Noyrod, W. Siangproh, W. Dungchai, S. Motomizu and O. Chailapakul, Anal. Chim. Acta., 2010, 668, 54-60.

28 Q. Liu, Z. Tang, B. Ou, L. Liu, Z. Zhou, S. Shen and Y. Duan, Mater. Chem. Phys., 2014, 144, 213-225.

29 M. X. Tan, L. Gu, N. Li, J. Y. Ying and Y. Zhang, Green Chem., 2013, 15, 1127-1132. 
30 M. X. Tan, Y. Zhang and J. Y. Ying, ChemSusChem., 2013, 6, 1186-1190.

31 D. Yang, P. Liu, N. Zhang, W. Wei, M. Yue, J. You and H. Wang, ChemCatChem., 2014, 6, 34343439.

32 M. X. Tan, Y. N. Sum, J. Y. Ying and Y. Zhang, Energy Environ. Sci., 2013, 6, 3254-3259.

33 J. Xu and B. Liu, Analyst, 1994, 119, 1599-1601.
34 E. Khaled, H. Hassan, I. Habib and R. Metelka, Int. J. Electrochem. Sci., 2010, 5, 158-167.

35 J. Zhang, B. P. Ting, N. R. Jana, Z. Gao and J. Y. Ying, Small, 2009, 5, 1414-1417.

36 B. P. Ting, J. Zhang, Z. Gao and J. Y. Ying, Biosens. Bioelectron., 2009, 25, 282-287.

37 Y. Si, Z. Sun, N. Zhang, W. Qi, S. Li, L. Chen and H. Wang, Anal. Chem., 2014, 86, 10406-10414. 